\title{
Friendly, but not "friends": Understanding and describing teacher-student relationship for productive and safe small group work
}

\author{
A. Gamble Blakey \& S. Chambers
}

\begin{abstract}
Introduction: Small group work is increasingly used as an educational tool in the health sciences and can have a potentially broad remit: to develop student knowledge and thinking, cultivate the values necessary for professional practice, but also, in doing so, to protect students from mistreatment. Small group teachers can, thus, find it hard to understand what an effective teacher-student relationship in small group teaching might "look like". We sought to identify, clarify and describe characteristics essential to an effective teacher-student relationship, aiming to add to literature about the type of relationship that helps a teacher reach educational goals but, specifically, one that fully addresses the potential risks of necessarily close teacher-student contact.
\end{abstract}

Method: As part of a larger action research project, we gathered qualitative data from: interviews with six medical teacher participants, observations and video-recordings of their teaching, participants' personal reflective journals and group discussions about teaching practice. We used a grounded theory approach to analyse our data.

Results: Over time, participants identified, tested and evaluated two essential characteristics to describe the teacher-student relationship that allowed teachers to meet their desired goals in small group work: 1) friendly and 2) not "friends".

Conclusions: This description of "relationship" for small group teaching is easily understood and pragmatic and, thus, potentially transferable across many health science small group teaching contexts.

Keywords: small group learning; medical education; relationship; mistreatment; bullying

Otago Medical School Centre for Early Learning, University of Otago, New Zealand

\section{Correspondence}

Dr Althea Gamble Blakey

Professional Practice Fellow and Research Fellow

Otago Medical School Centre for Early Learning

Sayers Building

Great King Street

Dunedin 9016

New Zealand

Tel: + 64272616423

Email: Althea.Blakey@otago.ac.nz 


\section{Introduction}

The small group has an important function in undergraduate medical education and is now widely accepted as a powerful, appropriate teaching method (Cooke et al., 2010). While the teacher of the small group can have numerous more specific learning aims, three broad goals are acknowledged as vital to the development of medical students' quality future practice:

1) Helping students develop and apply knowledge, thinking and understanding (Cooke et al., 2010; Golding, 2011; Wilson \& Cunningham, 2013)

2) Cultivating students' values for professional practice (Cooke et al., 2010; Golding, 2011; Wilson \& Cunningham, 2013)

3) Protecting students from mistreatment (Berryman, 2015; Plaut, 1993; Plaut \& Baker, 2011)

In this paper, we explain how a group of medical teachers raised and addressed a research question about effective teacher-student relationship in small group teaching. We do this to help teachers conceptualise their teacher-student relationship and, ultimately, be guided to create groups allowing these three important educational goals to be achieved.

Small group teaching is usually selected because it is a method that permits and encourages teaching and learning to be an interactive, social process (Harland, 2012; Vygotsky, 1978). These processes are essential for generating discussion and sharing thinking and ideas as a prelude to the learning that ideally follows (Biggs \& Tang, 2011). Because relationship can be a profound influence on these processes, as well as the achievement of learning goals, creating the "right" teacher-student relationship in this unique context is vital (Berryman, 2015; Harland, 2012; Vygotsky, 1978). According to some (e.g., Harden \& Laidlaw, 2016; Palmer, 2007), the power of the "right" relationship can be such that it becomes more important than a teacher's pedagogic skill, knowledge or understanding of a topic.

The literature provides copious guidance about the "right" teacher-student relationship in relation to the first goal we identified (helping a student develop their thinking, knowledge and understanding). Various characteristics of such a relationship are offered, for example, one in which the teacher is approachable, willing to discuss questions and encourages students to think independently (Biggs \& Tang, 2011; Golding, 2013; Tiberius, 2013) and that the relationship needs to be "positive" (Haidet \& Stein, 2016) or "high quality" (Biggs \& Tang, 2011). While useful, these descriptions also seem somewhat broad, and their lack of specificity provides little practical guidance for what a teacher might actually do in the classroom. For example, "positive" might be understood to mean a teacher's mood, the manner in which their classroom teaching skills are employed or the emotion a teacher tries to incite in their students.

The literature also offers guidance about the second goal we described, cultivating student values. We find guidance about which values a small group teacher might aim to cultivate in students for excellent future practice, e.g., empathy, kindness and respect 
(Cooke et al., 2010; Cruess et al., 2014; Palmer, 2007). The literature also indicates a general acceptance that values might be cultivated by a teacher "teaching" them implicitly — by students' observations of their teacher's conduct - as well as explicitly, in more deliberate acts (Burbules, 2008; Horsfall et al., 2012; Palmer, 2007). Evidence about how the latter might be managed by a teacher is also beginning to come forward in the literature (Gamble Blakey \& Pickering, 2018), with evidence to suggest that this potentially sensitive task can benefit from using a specific discourse in classroom dialogue. Ongoing discussions about student experiences of the hidden curriculum as part of teachers' implicit acts also serve to illustrate the importance of a teacher's implicit and explicit behaviours (Hafferty, 1998).

It is more challenging to elicit guidance from the literature about how to effectively address the third goal, to safeguard a student from mistreatment or bullying in the small group (see later for a working definition of these terms). The historical "master and servant" (Larkin \& Mello, 2010, p. 752) teacher-student relationship has arguably declined significantly in many teaching contexts, in favour of relationships resembling a partnership between the two (Larkin \& Mello, 2010). This decline seems appropriate given both the goal of developing teacher-student dialogue as a teaching method and the need to avoid potential issues with abuse of hierarchy in teaching.

Literature on how students might be protected from bullying as part of the teacherstudent relationship in small groups is emergent (Palmer, 2007; Plaut \& Baker, 2011). Some literature broadly acknowledges the possibility that a student might be mistreated in small groups (Recupero et al., 2004), but most focus on how to administer a formal bullying "intervention", for instance, aimed at changing a teacher's potentially sexist behaviour (Einarsen et al., 2011; see also Gamble Blakey et al., 2019).

Given the understanding that everyone would generally be better off strategically preventing bullying behaviours, rather than getting to the point where they are dealt with reactively (McGregor, 2015; Vartia \& Leka, 2011), it seems vital to pre-emptively educate teachers by describing a healthy and effective teacher-student relationship from the outset of their work (Donlan, 2014). This education seems doubly important when one considers the long-term contact that some teachers and students might have, for example, those who teach specific student groups over the whole academic year. This sustained contact, while great for learning, can also create the potential to damage student learning and mental health (Fnais et al., 2014). Pursuing a description of relationship that avoids this potential will likely allow some teachers to negotiate the challenges of "boundary issues" (see Plaut \& Baker, 2011, p. 828) at the outset of their relationship with students and increase the likelihood that mistreatment is avoided.

\section{Importance of research}

"Relationship" is relevant to several topics in undergraduate health professional education, also identified in the goals for small group teaching outlined above: small group pedagogy, personal values teaching and a subset about student mistreatment (Fnais et al., 2014; Henley et al., 2018). To this literature, we add a description of 
relationship that is pragmatic and easy to understand, especially to teachers new to small group teaching or struggling with challenges in approaching, developing or sustaining an appropriate teacher-student relationship. In summary, the current study is important because:

- small group teaching in medical education is an established, useful and growing practice (Cooke et al., 2010)

- the teacher is generally responsible for the development of the "right" teacherstudent relationship (Plaut \& Baker, 2011) and thus requires guidance to do so

- students can occupy a vulnerable position in small groups and in education more generally (Berryman, 2015). Any experience of bullying can have a detrimental effect on the learner, but some (e.g., younger students) may also have not yet developed the resilience to deal with it (Crampton et al., 2015; Curtis et al., 2007)

- any act of enculturation into practice can influence the "kind of doctor" a student becomes (Cruess et al., 2014; Larkin \& Mello, 2010); therefore, how students learn about interpersonal and professional relationships via small group experiences is important to their developing practice

- student bullying is a significant, ongoing worldwide concern and takes many forms, including academic neglect (Fnais et al., 2014). In this study, we identify one way this type of bullying might be prevented

- some teachers are at higher risk of forming inappropriate relationships with their students (Gordon et al., 1992), e.g., those who are depressed or burnt-out, new to a job or where they receive little guidance in possible implications (Gordon et al., 1992; Larkin \& Mello, 2010; Plaut \& Baker, 2011). These teachers might benefit from an understanding of the teacher-student relationship presented here

- some teachers hold personal values that can result in accidental or purposeful student bullying, especially if they have been mistreated themselves (Longo, 2013; Vessey et al., 2009). Given the prevalence and incidence of bullying in some professions (e.g., medicine, see Fnais et al., 2014), some incumbent teachers may also benefit from the work presented here.

\section{Defining terms}

Relationship: We use a definition of relationship described by our teacher-participants, i.e., the ways two or more people connect, act towards, behave with and regard each other.

Inappropriate: We use "inappropriate" to describe elements of a relationship that are emotionally, mentally or physically harmful. Here, we refer to elements that harm a student's learning (e.g., their achievement of the three learning goals identified) or mental state.

Friendly: We use "friendly" as a term to illustrate "kind" acts between people, such as gentle humour, guidance and enquiry into wellbeing. 
Not friends: refers to the avoidance of possible inappropriate connections, for example:

- a private non-learning phone call versus a phone call to check on whereabouts during class

- coffee with an individual student to catch up with chit chat versus exploring a learning issue, perhaps where only done with selected students

- dinner at a teacher's house versus an end of semester snack shared by the group.

We accept that our use of "friendly" but not "friends" to describe teacher-student relationship might not accurately capture all acts, especially in various cultural contexts. We also accept that long-term inculcation into clinical practice as an adult learner (for instance, those being promoted) might mean that boundaries between teacher and learner change or become less distinct. We intend the current work to be a "starter" guide for the undergraduate classroom teacher or other health science educator, especially those who are new or struggling in this role. We offer a description and practical application of:

finding a balance between the closeness that is necessary to provide good mentoring, and the necessary distance that allows the teacher to perform his or her function in an objective manner while not coercing the student into engaging in relationships that might be academically or psychologically harmful. (Plaut \& Baker, 2011, p. 832)

Student mistreatment or bullying: We use the following definition of student mistreatment/ bullying, as it explicitly includes a focus on the learner's positioning within the possible hierarchy in many teaching and learning contexts:

Mistreatment, either intentional or unintentional occurs when behaviour shows disrespect for the dignity of others and unreasonably interferes with the learning process. Examples of mistreatment include sexual harassment; discrimination or harassment based on race, religion, ethnicity, gender or sexual orientation; humiliation; psychological or physical punishment; and the use of grading and other forms of assessment in a punitive manner. (Mavis et al., 2014, p. 706).

\section{Methods}

Our overall methodological framework was qualitative participatory action research. Teacher-participants were purposively selected (Kitzinger, 1995) as experienced clinical staff (nurses, doctors, allied health) with substantial experience teaching small groups of students in the classroom (further description of demographics would compromise participant anonymity) at one medical school. Over 1 year, five teacher-participants and one researcher-teacher, total six, each worked with several small groups of students ( -10 per class) in the early years of the MBChB (medical degree) program.

Teachers taught students aged 17 years old and upwards, most of whom had completed a health sciences foundation year. Other students entered the medical program from a related health profession or by undertaking requisite science courses for acceptance (where these students had entered from non-health professions). In the early years, 
the medical curriculum has the primary goals of developing a student's clinical skills, thinking and values for professional practice, e.g., to help a student develop skills to assess a patient's symptoms and context, arrive at a differential diagnosis and develop/ act on knowledge and values to effectively treat the patient. Students take three small group classes per week ( 2 hours each) over one academic year, with these specific goals. Each class has a different remit and its own teacher. Thus, teachers in the study taught the same group for 2 hours every week for one academic year.

The wider project was framed with a theory of thinking developed from Barnett's (1997) theory of critical being, which was developed in Blakey's $(2011,2016)$ and Blakey et al.'s (2014) research. The wider project enabled us to further develop this theory and examine its application in medical small group teaching. The current study is part of this research but can be understood without reference to the theory itself.

\section{Methodology}

Action research (AR) can be used to solve a problem or address a question about practice (Herr \& Anderson, 2014), in this case, teacher practice in small groups. AR can seem complex, but its value lies in allowing participants to iteratively research questions together. AR offers copious opportunities to attempt solutions with the attendant support, knowledge, critique and experience of a wider research group (Herr $\&$ Anderson, 2014). AR also allows questions and sub-questions about practice to be raised by participants throughout. At the study outset, and as part of a broader question, teacher-participants raised the question How might we simply and accurately characterise an effective and safe teacher-student relationship for our learning goals in the small group?

This question was addressed in iterative processes of discussion, developing and testing ideas (potential answers). Foci of discussion around this question in practice were: What does the teacher and student need to achieve in the small group? What kind of relationship might allow them to do this? What characteristics might best describe this relationship? Incidents that teachers had experienced in the past, and during the study, were discussed as relevant to the question. After suggesting, discussing and refining ideas over a year, teacher-participants reached a mutual, useful understanding that answered their research question. We describe the development of this thinking alongside quotes from individual teachers (pseudonyms), and in some cases, to aid clarity, the researcher's summaries of group members' thinking. We selected quotes from the data set that were most illustrative of each point, rather than those that were evenly representative of all participants.

Data were gathered from several perspectives: observations and video recordings of teaching as well as an interpersonal process recall (IPR) (Kagan et al., 1969; Lyle, 2003) session for each teacher. IPR allows a participant the opportunity to observe, reflect and comment on their own practice via watching a recording of their practice and offering the researcher a recorded commentary. In doing so, they are offered opportunity and time to think about their practice, which is not available in the moment itself (Kagan et al., 1969). 
Data were also gathered from individual unstructured teacher-participant interviews, with a focus on asking about current teacher practice and emerging issues (and about the use of the theory framing the research, not reported here). We also recorded formal meetings (monthly) and field notes about informal teaching discussions, and some teachers kept reflective journals about their teaching practices and experiences (used variously from every day/every week/infrequently). Especially valuable data sources for the current descriptions were the audio recordings of monthly research meetings, particularly to document iterative discussion processes that illustrated how teachers evaluated and refined answers to research questions. This research was granted approval by the University of Otago, New Zealand, Human Ethics Committee.

\section{Data analysis and researcher positioning}

Data were collated, transcribed and imported into the data management programme NVivo (C and themes identified, developed and refined to be those best representing ideas, or groups of ideas, at specific moments in time. Methodology was, thus, inductive and emergent-we sought answers to our research question with little initial idea of what data might elicit and how this might develop over the research year. Using a grounded theory approach (Conrad, 1982), we continued our analysis until a point of thematic saturation, the point at which all data were assigned a theme that accurately conveyed their meaning and no new categories arose (Fusch \& Ness, 2015).

As is usual with AR, one researcher (first author of this paper) was a teacher-participant rather than just an observer of this research (Herr \& Anderson, 2014). This positioning allowed the researcher not only to suggest solutions to problems/questions based on her own practice as a small group teacher but also to experience and gain insight into processes and solutions posed by others.

\section{Results}

First, we describe the evolution of our specific research question, an evolution which is normal in action research. In presenting our results, we offer quotes and summaries of participant data. These are analysed versions of question and answer processes, undertaken by teachers of health professionals, about many different issues in practice in classrooms the world over.

\section{Emergence of specific research question ("problem")}

Our research question was first raised by two teacher-participants who (in a monthly meeting) discussed concerns about the nature of a colleague's teacher-student relationship. Initial thoughts conveyed by other teacher-participants were summarised as they understood this relationship to be somehow "wrong", informed by their significant experience of how relationships might affect learning:

There's something not right about it [the teacher-student relationship], isn't there, it's a bit dodgy [meaning dubious, deceitful or harmful]. I'm sure it's not good for learning, going out for drinks like that. It will have an effect on the classroom stuff, right? (personal communication Jane to Lance, March meeting) 
During the next three monthly teacher-participant meetings, these two teacherparticipants observed that their concerns about the above, and other teacher-student relationships, were shared by the whole participant group, and they began to report specific reasons for these concerns. These included, for example, teachers' social media contact with students (Twitter, Facebook, etc.) and teachers who invited students for drinks in the evening or dinner at their home. One specific example was about the use of Facebook and "discussion groups" that some teachers had created to help students' learning (e.g., to discuss complex cases). After some discussion, the contact afforded by these groups was deemed inappropriate because (when using their "home" profile), it allowed teachers and students access to personal information and photographs that were deemed "private, that kind of thing should be for friends only. That's why I'm not on Facebook, and I wouldn't be friends with my students if I was" (personal communication from Lance, recorded in field notes after the April meeting).

After raising this issue in subsequent discussions, and recording their thinking in personal journals, some teachers noted that it was the potential "closeness" of "going for drinks" or Facebook contact (etc.) that would be inappropriate, specifically because "closeness" seemed incongruent with some goals for student learning. By email, teacherparticipants went on to discuss closeness relative to the important learning goals that they had identified as their main remit, and the three goals outlined above were brought to and discussed in the teacher-participant group.

In summary, teacher-participants understood that they should help students develop their thinking, knowledge, etc. Similarly, they understood certain values to be essential to good practice and acknowledged the power of "values teaching" done implicitly as part of their own behaviour. Two teachers also reported doing some reading about this topic as a result of being involved in the research. However, in apparent echo of the literature, teachers reported feeling sure that the third goal about student mistreatment was part of their role but also feeling uncertain about how to best achieve this goal. They seemed to understand that the use of Facebook or "going for drinks", etc. could somehow interfere with this goal, that a closeness developed as a result of these acts might place a student at risk of mistreatment. While not mistreatment or bullying to such a degree as that described by some (e.g., Gordon, et al., 1992), teachers reported understanding that mistreatment due to closeness could potentially negatively impact a student's learning and that they still needed to define where the boundaries of teacherstudent relationships should to be placed. This placement was to ensure students would work well in small groups but also to avoid the potential for them to be mistreated by their teacher.

We now describe, in detail, the three goals that teacher-participants identified as important for student learning. Understanding and articulating these goals was a necessary part of the teacher-participants' process of arriving at an answer to the research question about teacher-student relationships. To illustrate how these goals developed from data, they formed the first foundational theme, simply called "teachers' goals/learning outcomes", identified in an NVivo@ (data handling program) "branch". Subsequently, the goals became distinct sub-branches, as a result of in-depth discussions 
about tutorial material across the year. The theme of "mistreatment", and preventing it in learning, emerged as a distinct category alongside that of developing knowledge and values for professional practice. After this, branches of these sub-branches were formed around what "helped" and what "hindered" the achievement of these goals, and the two characteristics of "friendly" but not "friends" began to occur regularly and then feature in all sub-branches.

We now describe teacher-participants' reasoning for the importance of each characteristic as part of students" education and their argument for each characteristic of "relationship" being important to achieving these goals. All descriptions are an important part of our results, which ultimately explain teacher-participants' identification and justification of each characteristic of "relationship" as an answer to the research question: How might we simply and accurately characterise an effective and safe teacher-student relationship for our learning goals in the small group?

\section{Three foundational goals for student learning}

The three goals identified were:

1) helping students develop and apply knowledge, thinking and understanding

2) cultivating positive values for professional practice

3) protecting the student from mistreatment.

\section{Helping students develop and apply knowledge, thinking and understanding}

The first foundational learning goal described by teacher-participants comprised a collection of sub-goals centred on the development and application of knowledge, thinking and understanding. Some examples of sub-goals were that a teacher might offer their own thinking to students to help them express ideas and spot errors in thinking, or teachers might join with students in humour to develop rapport and aid discussions about feelings and hard-to-express or complex issues, such as reflective thinking. Similarly, teachers might offer emotional support and encouragement when trying to help students overcome general anxiety about talking in the small group.

Teacher-participants also identified a group of sub-tasks essential to helping their students develop knowledge, thinking and understanding. These were associated with various degrees of discipline, or "being firm". Examples included:

- intervening in group process to help a student understand unacceptable behavior that prevented the learning of other students

- helping a student understand how to improve work (e.g., an essay) that fails to reach the required standard

- keeping a student "working at it" in class when this is understood to be the best way to help the student learn, perhaps by being firm with a student who needs to "keep trying" to make progress but doesn't wish to. 
According to Lance, a teacher-participant:

It's the art and the craft of what we do, isn't it? We have to do all of these things [Lance's emphasis, in reference to ideas discussed as above] and know when to do them. It's not simple, but then again, students aren't simple either. (April teacher-participant group meeting)

Justification/reasoning for the two characteristics of teacher-student relationship ("friendly" but not "friends") to achieve this goal

Teacher-participants explained and justified the necessity for both characteristics of "relationship" to help students develop their knowledge, thinking and understanding. As a way of illustrating this necessity, teacher-participants described what might happen if teachers failed to develop such a relationship, i.e., if a teacher was not friendly or if they were indeed "friends" with their students. These reasons help reinforce why, ultimately, we understand the conceptualising of characteristics of an effective teacherstudent relationship to be useful and necessary, and worth researching.

Lance reported experiences of "unapproachable and unfriendly" tutors, who failed to create a relationship that he understood to be requisite for optimal small group learning. He offered several examples. Lance suggested that being unfriendly might render a collegial teacher-student discussion less likely to develop, with the student failing to learn to think as well they might, particularly in regard to topics that can be difficult to discuss, e.g., alcohol use or death. Lance also talked about the "dreaded needy tutor" and the "closeness" (e.g., emotional) that might result from friendship with students, which might render the teacher "unable, or at the very least very, very uncomfortable and reluctant" to facilitate some sub-goals of learning and applying knowledge, thinking and understanding, specifically, those related to discipline. The necessity of discipline, and what might happen if teachers failed to provide it, was also summarised by Jane, in conversation with Lance:

Jane: You've just got to be able to tell them [students] to pull their heads in [behave] and get on with it from time to time; that's our job. It's not a very nice bit of it, but can you imagine if we didn't? They would just learn to misbehave all the time or to be spoon fed every little thing, and they would never be able to do it themselves. It would be so much harder if we were all buddies and we were afraid of saying that kind of thing. It would hurt everyone's feelings so you wouldn't be able to do it very well.

Lance: I know. You know, I see X [staff member] tries so hard to be best friends with everyone, probably still thinks of themselves as a student themselves, but it means that they [the students] won't ever learn what they need to. It's painful to watch, but it's true.

Lance further explained the influence of "friendship" between teachers and students on student learning, and the teacher in this relationship would do the student a disservice in the long term because a close emotional bond between a teacher and a student would simply "get in the way of what it is we as teachers are actually here to do ... and make discipline difficult". Similarly, Frances talked about how "telling a student off" would "really hurt" a student with whom a teacher is friends and, therefore, would 
likely be avoided. Ultimately, Lance summarised that one result of a teacher's failure to administer discipline, or a lesser version, such as "keeping them at it", would be a student's failure to learn.

\section{Cultivating positive values for professional practice}

Teacher-participants understood that cultivating students' values, e.g., respect, honesty, kindness and empathy, was a major task for a small group teacher. These values were understood to be important to both students' learning and their ongoing development as professionals. One example of this was given by Eleanor, who explained how values might be learned by students both implicitly and explicitly. She described how a teacher might explicitly cultivate students' values by discussing the reasoning for small group work but also by respectfully listening to students' opinions, implicitly "teaching" them that their thinking is valued alongside the thinking of others.

Justification/reasoning for the two characteristics of teacher-student relationship ("friendly" but not "friends") to achieve this goal

As with the first goal, teachers offered examples to support the claim that they were required to develop students' values by employing the "what if teachers didn't develop this characteristic" argument. For example, teachers expressed their understanding that failure to develop a "friendly" teacher-student relationship might implicitly teach students that a doctor should be "unfriendly and distant", a "passive observer" of patients, ultimately rendering the formation of a functional, therapeutic relationship difficult. Teachers also discussed how a teacher developing a close "friends" relationship with a student might indicate to the student that a professional doctor-patient relationship might also be "close", perhaps leading to an unhealthy degree of involvement for either the doctor or patient.

\section{Protecting the student from mistreatment}

The final broad goal identified by teacher-participants was to protect students from mistreatment. Teacher-participants had considerable experience in the clinical workplace and were familiar with the potential for overtly inappropriate behaviour, such as sexual harassment, and more subtle mistreatment, such as exclusion or favoritism. Teacherparticipants understood students to be naturally at risk of mistreatment in the studentteacher relationship because of the inherent power gap between them but realized, perhaps anew, that a common, seemingly harmless, act such as being "friends" (perhaps even "friends" on Facebook) might also be considered a form of student mistreatment.

Justification/reasoning for the two characteristics of teacher-student relationship ("friendly" but not "friends") to achieve this goal

Teacher-participants understood both characteristics identified to be useful to protect students from mistreatment, but the second, "not being friends", significantly so. They offered examples of both. For example, teacher friendliness can help keep a student safe from mistreatment because a friendly relationship will encourage open 
discussion of concerns and help students develop wellbeing and resilience to cope with mistreatment should it happen elsewhere. The potentially powerful effect of avoiding being "friends" was first reported by teachers as essential for the preservation of fairness, for example, to ensure each student is offered similar opportunities and attention rather than a "favourite" student being treated differently. However, teachers were especially concerned that being "friends" would satisfy the teacher's need for social contact at the expense of a student's personal and learning needs, for instance, if a teacher were to take a student out to the pub as a friend. Teachers explained that being "friends" might be understood as an act of mistreatment because:

- this act can implicitly suggest to a student that the teacher is pursuing and prioritising their own interests over the student's learning, and the emotional ties of friendship can render a teacher reluctant to pursue certain important goals for student learning, such as administering discipline about behaviour in the group

- it can be hard for a student to refuse a request of friendship by a teacher due to the inherent power gap in the teacher-student relationship (Biggs \& Tang, 2013)

- a student might feel they are in such a friendship under some duress, "used" or coerced to fulfill a teacher's needs, and at the same time, that their learning is being compromised by the teacher.

In short, teacher-participants understood that a relationship characterised by being "friends" would be both incongruent with their students' learning needs and potentially represent a form of mistreatment. Lance described his thinking that the student would likely be aware of this, adding to potential distress:

Whose needs are really being served by such a friendship? It's not the student's, that's for sure, not deep down. It's the teacher's. They want to feel liked or dare I say, needed, but the student will be able to tell that doing this [being close in a friendship] means also that it would be very hard for the teacher to attend to the student's best interests in the end. They wouldn't fail their essay or give honest feedback when it is needed, and it's not what we are here for. We're here to support them through the course and prepare [them] for their clinical years. Full stop. (in conversation with Jane)

\section{Why is it so hard?}

At the conclusion of this research project, teacher-participants had reached a point at which they felt able to offer further supporting information for their reasoning about "friendly" but not "friends", further explaining the arguments reported above.

In the final group meetings, in review of the findings and issues reported, teachers discussed why achieving either characteristic might actually be hard for teachers and students. In doing so, they offered further evidence about why the current research might be justifiable, necessary and worth reporting. Teacher-participants reported that a small group teacher might find it hard to be friendly because they may:

- dislike the small group context or feel under pressure, or obligated, to teach such classes and, thus, fail to invest effort in "being friendly" 
- have fixed ideas about teaching, perhaps to singularly include lecturing as an effective teaching method

- be overworked or burnt out

- not be a naturally friendly or trusting person

- have fixed beliefs about relationships, e.g., that an effective teacher-student relationship might instead mean being "in charge" or "aloof", where either might actually preclude friendliness.

Teachers also described experiences where issues emanating from their students prevented them being "friendly". The student may:

- express dislike for being taught in a small group or the topic taught in it, and this may play out in a failure to reciprocate teachers' friendliness

- not reciprocate teachers' friendliness because of a lack of experience with this

- not reciprocate teachers' friendliness if they have contrasting beliefs about the nature of the teacher-student relationship

- use the small group inappropriately, perhaps as a forum to singularly express their opinions (but not listen to those of others), and a teacher might find it hard to respond in a friendly manner

- experience a "personality clash" with the teacher, perhaps exacerbated by close contact over time.

Teacher-participants in this study also reported experiences in which it was hard to resist becoming friends with some students. In several data sources (personal journals, monthly discussion groups, individual interviews at study end), teacher-participants (Lance, Jane, Frances, Eleanor and John) explained that:

- some older students tend to approach teachers "as a friend", and teachers felt rude declining

- being friends with students reminded some teachers of enjoyable undergraduate experiences, recollections of which were confidence building

- friendship can be enjoyable, especially where some teachers and students are of similar age and compatible in their sense of humour or enjoyment of each other's company

- increasing use of social media as teaching tools (e.g., a "clinical cases discussion group") lend themselves to closer relationships due to access to personal information (in response, some teachers set up "professional" profiles with limited personal detail)

- teachers felt that friendship "at work" offered pleasures otherwise unavailable, or not obtained by patient contact in another (clinical) job. 


\section{Discussion}

The three broad goals for teaching in small groups outlined by our teacher-participants are mostly well supported by the literature. For example, helping students develop and apply thinking, knowledge and understanding in the small group is supported by works across medical and nursing education (Cooke et al., 2010; Cruess et al., 2014; Kitchen, 2013), higher education (Golding, 2011; Harland, 2012; Harland \& Pickering, 2011) and professional practice (Wilson \& Cunningham, 2013). Similarly, literature supports the goal of cultivating values for professional practice (Cooke et al., 2010; Golding, 2011; Wilson \& Cunningham, 2013), with the understanding that this is part of a teacher's "job", which we can teach implicitly-whether we mean to or not (Palmer, 2007). Similarly, the role of the characteristics "friendly" but not "friends" are acknowledged in the literature. For example, Golding (2013) and Kitchen (2013) both note the need for a teacher to be friendly but also to be firm in order to help students develop their long-lasting tenacity in learning and a habit of in-depth thinking.

However, protecting students from mistreatment is a point rather more generally made (see Berryman, 2015; Plaut, 1993; Plaut \& Baker, 2011), and we find little evidence of the downsides of the teacher-student relationship extending to being "friends". For example, Kind et al. (2014) discusses the benefits of a friend-like relationship, as a "professional friend" (e.g., mentor, teacher), and that the extension of teacherstudent relationship to that of an actual "friend" can have negative outcomes for either. The current study goes further, outlining what exactly might happen (consciously or unconsciously) should this line be crossed; we explain how a student with insight into the latter phenomenon might suffer from academic neglect but also from the knowledge that their teacher valued the students' learning less than the fulfilment of their own social needs.

Some of our findings could be said to be partially speculative, because we did not directly gather data from students. For example, we did not ask students about their experiences or feelings about over-friendly teachers. However, our results are based on the cumulative thinking of teacher-participants with a significant amount of experience and expertise, and from ideas tested over an extended period. Thus, we feel that the possibility for mistreatment in "friendship" is an important issue that is worth describing. We also suggest this idea be pursued in further research given the current prevalence of general student mistreatment (Fnais et al., 2014). This type of "taking advantage" might be considered indicative of future bullying acts of a more severe nature. We might also extend this inquiry to the student who is not "brought into line", for instance, by an over-friendly teacher who fails to administer appropriate discipline, for example, in regards to respecting the viewpoints of peers in the group teaching setting. The latter line of research is supported by literature that indicates a student who misbehaves in training is more likely than most others to misbehave while in practice (Papadakis et al., 2008).

Our chosen methodology (action research) might create weaknesses in this research as it is relatively uncommon in medical education, and as such unfamiliar to participants, 
or as Lewin (1952) summarises, disconcerting to researchers because of its tendency for data collection and subsequent analysis to be rather chaotic and tricky to manage. However, we feel reassured in our choice because a significant depth and breadth of data was obtained with which to identify and address our questions (practices that are normal in action research) and triangulate our findings between teachers and classes. While small, our sample size was appropriate for our goal to find rich, in-depth qualitative data; a larger sample would likely present challenges (and some irony) in regard to forming appropriate relationships with participants and being able to hear what they had to say.

There may also be some weaknesses associated with researcher positioning in this research. As is usual with $\mathrm{AR}$, one researcher (first author of this paper) was a teacherparticipant rather than just an observer of this research. This necessary involvement required the implementation of strategies to ameliorate reporting bias, e.g., the teacherresearcher needed to ensure their ideas did not unfairly dominate the research and that all participants were encouraged to engage and contribute as fully as possible. Thus, the researcher assured teacher-participants that 1) their input was valuable 2) this study was being undertaken for all to learn from each other and 3) the overall purpose of the research was to examine, improve and enhance teaching and learning, and as such, the teachers would not be judged as good or bad teachers. We also undertook member checking in cases where we were unsure of meaning or outcome (for example) of a discussion (see Birt et al., 2016). Such occasions were rare, as the researcher was present for all of the discussions and recordings and was able to confidently recall the context.

Overall, we are offered confidence in our results for several reasons: 1) some teachers reported that prior to the current study they had found it hard to understand what kind of relationship would work best in the small group; that teachers had given this question some considerable prior thought offers a sense of pragmatism and legitimacy to our research question, 2) because the features of relationship that we discuss here were reportedly adopted and applied to practice by all teacher-participants, subjected to discussion and critique and met with apparent success, 3) because the combined experience and expertise of our purposively sampled teacher-participants was considerable and 4) our large, diverse data set allowed substantial triangulation of results from multiple sources. For example, features of a teacher-student relationship observed and described by a researcher could be triangulated with a teacher's reflection on their practice, plus discussion and critique by other teacher participants, who then further tested these ideas as part of their own practice.

While the results we report here may be transferable to some other small group teaching contexts, especially those with a values component and/or in healthcare, we do have to be careful about the generalisability of results-they emanate from a specific context and a specific teacher group. Our conclusions might not be easily generalisable to teaching with different goals to those described here or larger group teaching with less teacher-student contact. We did not research the latter specifically, but there may be times that findings might be useful, e.g., to a lecturer who holds a small revision group for students. 


\section{Conclusion}

In this article, we describe how our teacher-participants responded to concerns about the effectiveness and safety of the teacher-student relationship in small group work. Essentially, teacher-participants sought reasoning for and positioning of the proper boundaries for a teacher-student relationship in small group teaching. There is substantial support in the literature for two of the broad teaching goals identified in this research and a growing justification for the third, about student mistreatment. Specifically, teachers described how friendliness was necessary for many facets of learning, but they also described the possible detriment to students if their relationship with a teacher was too close. Specifically, teacher-participants raised the possibility that such a relationship might be a mistreatment of the student, and the student might suffer in academic and personal terms from such a relationship. In summary, a small group teacher needs to be friendly with their students to facilitate the best learning but cannot take this friendliness to friendship without neglecting learners' requisite needs.

The two characteristics of "friendly" and not "friends" seem feasible, useful and understandable and are supported here by examples from practice in quote form and in summary. Beyond descriptions of the "professional friend" (Dahlgren et al., 2006), our results offer practical assistance to teachers wishing to ensure they act on students' best interests, helping them learn and go on to be good health professionals. We suggest the development of a "friendly" but not "friends" relationship as a useful focus of professional development opportunities, especially for teachers under stress, those new to teaching students in the small group context and those experiencing challenges such as increasing use of social media as an educational tool.

\section{Acknowledgements}

The primary author would like to acknowledge the assistance of an Otago Medical School, Medical Education Scholarship for the support of research reported in this article, and a University of Otago PhD Publishing Bursary for support during its writing. Thanks also to Clinton Golding (Otago), Neil Pickering (Otago) and Tim Wilkinson (University of Otago in Dunedin and Christchurch) for supervisory support in the development of ideas expressed in this article.

\section{Funding and conflicts of interest}

The authors declare no conflicts of interest between this article and our personal or professional interests.

\section{References}

Barnett, R. (1997). Higher education: A critical business. Open University Press.

Berryman, E. (2015) Bullying culture: Valuing the teacher-student relationship. New Zealand Medical Journal, 128(1424), 13-17. https://global-uploads.webflow.com/ 5e332a62c703f653182faf47/5e332a62c703f632bb2fd765_NZMJ-1424.pdf 
Biggs J., \& Tang C. (2011). Teaching for quality learning at university (2nd ed.). Open University Press.

Birt, L., Scott, S., Cavers, D., Campbell, C., \& Walter, F. (2016). Member checking: A tool to enhance trustworthiness or merely a nod to validation? Qualitative Health Research, 26(13), 1802-1811. https://doi. org/10.1177/1049732316654870

Blakey, A. (2011). Experiences of critical thinking, critical action and critical being in health science tutorials [Unpublished master's thesis]. University of Otago.

Blakey, A. (2016). Cultivating student thinking and values in medical education: What teachers do, how they do it and who they are [Unpublished doctoral dissertation]. University of Otago.

Blakey, A., Harland, T., \& Kieser, J. (2014). Critical thinking, critical action and critical being in health science tutorials. Focus of Health Professional Education, 15(3), 22-31. https://pdfs.semanticscholar. org/5e1c/f1dc750417937140216b91e320d1626df0d6.pdf?

$\mathrm{ga}=2.171426848 .1400678186 .1585872850-71417460.1585722561$

Burbules, N. (2008). Tacit teaching. Educational Philosophy and Theory, 40(5), 666-677. https://doi.org/10.1111/j.1469-5812.2008.00453.x

Conrad C. (1982). Grounded theory: An alternative approach to research in higher education. The Review of Higher Education, 5(4), 239-249. https://doi. org/10.1353/rhe. 1982.0010

Cooke, M., Irby, D., \& O'Brien, B. (2010). Educating physicians: A call for reform of medical school and residency. Jossey-Bass.

Crampton, P., Wilkinson, T., Anderson, L., Walthert, S., \& Wilson, H. (2015). Bullying in health care settings: Time for a whole-of-system response. New Zealand Medical Journal, 128(1424),10-13. https://global-uploads.webflow.com/5e332a62 c703f653182faf47/5e332a62c703f632bb2fd765_NZMJ-1424.pdf

Cruess, R., Cruess, S., Boudreau, J., Snell, L., \& Steinert, Y. (2014). Reframing medical education to support professional identity formation. Academic Medicine, 89(11), 1446-1451. https://doi.org/10.1097/ACM.0000000000000427

Curtis, J., Bowen, I., \& Reid, A. (2007). You have no credibility: Nursing students' experiences of horizontal violence. Nurse Education Practitioner, 7(3), 156-163. https://doi.org/10.1016/j.nepr.2006.06.002

Dahlgren, L. O., Eriksson, B. E., Gyllenhammar, H., Korkeila, M., Sääf-Rothoff, A., Wernerson, A., \& Seeberger, A. (2006). To be and to have a critical friend in medical teaching. Medical Education, 40(1), 72-78. https://doi.org/10.1111/ j.1365-2929.2005.02349.x

Donlan, L. (2014). Exploring the views of students on the use of Facebook in university teaching and learning. Journal of Further and Higher Education, 38(4), 572-588. https://doi.org/10.1080/0309877X.2012.726973

Einarsen, S., Hoel, H., Zapf, D., \& Cooper, C. (2011). The concept of bullying and harassment at work: The European tradition. In S. Einarsen, H. Hoel, D. Zapf, 
\& C. L. Cooper (Eds.), Bullying and harassment in the workplace: Developments in theory, research, and practice (2nd ed.) (pp. 3-39). CRC Press.

Fnais, N., Soobiahm, C., Chen, M., Lillie, E., Perrier, L., Tashkhandi, M., Straus, S., Mamdani, M., Al-Omran, M., \& Tricco, A. (2014). Harassment and discrimination in medical training: Systematic review and meta-analysis. Academic Medicine, 89(5), 817-827. https://doi.org/10.1097/ACM.0000000000000200

Fusch, P., \& Ness L. (2015). Are we there yet? Data saturation in qualitative research. Qualitative Report, 20(9), 1408-1416. https://cpb-us-e1.wpmucdn.com/sites. nova.edu/dist/a/4/files/2015/09/fusch1.pdf

Gamble Blakey, A., \& Pickering, N. (2018). Putting it on the table: Towards better cultivating medical student values. Medical Science Educator, 28(3), 533-542. https://doi.org/10.1007/s40670-018-0584-8

Gamble Blakey, A., Smith-Han, K., Anderson, L., Collins, E., Berryman, E., \& Wilkinson, T. J. (2019). Interventions addressing student bullying in the clinical workplace: A narrative review. BMC Medical Education, 19(1), 220-233. https:// doi.org/10.1186/s12909-019-1578-y

Golding, C. ( 2011). Educating for critical thinking: Thought-encouraging questions in a community of inquiry. Higher Education Research and Development, 30(3), 357-370. https://doi.org/10.1080/07294360.2010.499144

Golding, C. (2013) The teacher as guide: A conception of the inquiry teacher. Educational Philosophy and Theory, 45(1), 91-110. https://doi.org/10.1080/00131 857.2012.715387

Gordon, G., Labby, D., \& Levinson, W. (1992). Sex and the teacher-learner relationship in medicine. Journal of General and Internal Medicine, 7(4), 443-447. https://doi.org/10.1007/bf02599165

Hafferty, F. (1998). Beyond curriculum reform: Confronting medicine's hidden curriculum. Academic Medicine, 73(4), 403-407. https://doi. org/10.1097/00001888-199804000-00013

Haidet, P., \& Stein, H. (2016). The role of the student-teacher relationship in the formation of physicians. Journal of General and Internal Medicine, 21(S1), S16S20. https://doi.org/10.1111/j.1525-1497.2006.00304.x

Harden, R., \& Laidlawm, J. (2016). Essential skills for a medical teacher: An introduction to teaching and learning in medicine. Elsevier Health Sciences.

Harland, T. (2012). University teaching: An introductory guide. Routledge.

Harland, T., \& Pickering, N. (2011). Values in higher education teaching. Routledge.

Henley, S., Horner, C., Wills-Smith, N., Paxtor, C., Perry, R., O'Cain, H., \& Roseborough, B. (2018). An opinion on mistreatment faced by student nurses during clinical. Journal of Psychosocial Nursing and Mental Health Services, 56(10), 6-8.

Herr, K., \& Anderson, G. (2014). The action research dissertation: A guide for students and faculty. Sage. 
Horsfall, J., Cleary, M., \& Hunt, G. E. (2012). Developing a pedagogy for nursing teaching-learning. Nurse Education Today, 32(8), 930-933. https://doi. org/0.1016/j.nedt.2011.10.022

Kagan, N., Schauble, P., Resnikoff, A., Danish, S., \& Krathwohl, D. (1969). Interpersonal process recall. Journal of Nervous and Mental Disorders, 148(4), 365-374. https://doi.org/10.1097/00005053-196904000-00004

Kind, T., Patel, P., Lie, D., \& Chretien, K. (2014). Twelve tips for using social media as a medical educator. Medical Teacher, 6(4), 284-290. https://doi.org/10.3109/01 42159X.2013.852167

Kitchen, M. (2013). Facilitating small groups: How to encourage student learning. Clinical Teacher, 9(1), 3-8. https://doi.org/10.1111/j.1743-498X.2011.00493.x

Kitzinger, J. (1995). Qualitative research: Introducing focus groups. British Medical Journal, 311, 299-302. https://doi.org/10.1136/bmj.311.7000.299

Larkin, G., \& Mello, M. (2010). Commentary. Doctors without boundaries: The ethics of teacher-student relationships in academic medicine. Academic Medicine, 85(5), 752-755. https://doi.org/10.1097/ACM.0b013e3181d7e016

Lewin, K. (1952). Group decision and social change. In G. Swanson, T. M.

Newcomb, \& F. Hartley (Eds.), Readings in social psychology (pp. 340-344). Henry Holt \& Co.

Longo, J. (2013). Bullying and the older nurse. Journal of Nursing Management, 21(7), 950-955. https://doi.org/10.1111/jonm.12173

Lyle, J. (2003). Stimulated recall: A report on its use in naturalistic research.

British Educational Research Journal, 29(6), 861-878. https://doi. org/10.1080/0141192032000137349

Mavis, B., Sousa, A., Lipscomb, W., \& Rappley, M. (2014). Learning about medical student mistreatment from responses to the medical school graduation questionnaire. Academic Medicine, 89(5), 705-711. https://doi.org/10.1097/ ACM.0000000000000199

McGregor, F-L. (2015). Bullying: The perspective of the accused. In A.-M. Quigg (Ed.), The handbook of dealing with workplace bullying (pp. 177-196). Gower.

Palmer, P. (2007). The courage to teach: Exploring the inner landscape of a teacher's life. Jossey-Bass.

Papadakis, M., Arnold, G., Blank, L., Holmboe, E., \& Lipner, R. (2008). Performance during internal medicine residency training and subsequent disciplinary action by state licensing boards. Annuls of Internal Medicine, 148(11), 869-876. https://doi. org/10.7326/0003-4819-148-11-200806030-00009

Plaut, S. (1993). Boundary issues in teacher-student relationships. Journal of Sex and Marital Therapy, 3, 210-219. https://doi.org/10.1080/00926239308404906

Plaut, S., \& Baker, D. (2011). Teacher-student relationships in medical education: Boundary considerations. Medical Teacher, 33(10), 828-833. https://doi.org/10.31 09/0142159X.2010.541536 
Recupero, P., Heru, A., Price, M., \& Alves J. (2004). Sexual harassment in medical education: Liability and protection. Academic Medicine, 79(9), 817-824. https:// doi.org/10.1097/00001888-200409000-00002

Tiberius, R. (2013). Small group teaching: A trouble-shooting guide. Routledge.

Vartia, M., \& Leka, S. (2011). Interventions for the prevention and management of bullying at work. In S. Einarsen, H. Hoel, D. Zapf, \& C. Cooper (Eds.), Bullying and harassment in the workplace: Developments in theory, research, and practice (2nd ed.) (pp. 359-380). CRC Press.

Vessey, J., Demarco, R., Gaffney, D., \& Budinm, W. (2009). Bullying of staff registered nurses in the workplace: A preliminary study for developing personal and organizational strategies for the transformation of hostile to healthy workplace environments. Journal of Professional Nursing, 25(5), 299-306. https://doi. org/10.1016/j.profnurs.2009.01.022

Vygotsky, L. (1978). Mind in society. The development of higher psychological processes. Harvard University Press.

Wilson, H., \& Cunningham, W. (2013). Being a doctor: Understanding medical practice. Otago University Press. 